\title{
El pluralismo axiológico de la ciencia ${ }^{1}$
}

\author{
JAVIER ECHEVERRIA \\ Depto. de Lógica y Filosofía de la Ciencia \\ Universidad del País Vasco
}

\section{Introducción}

Resulta común leer que, de existir valores que rijan la actividad científica, y de ser importante su estudio filosófico, los únicos que deben interesar a los filósofos de la ciencia son los valores cognitivos o epistémicos. ${ }^{2}$ Según estas posturas, la búsqueda de conocimiento científico está determinada exclusivamente, o al menos prioritariamente, por valores tales como la verdad, la coherencia, la simplicidad o la capacidad predictiva y explicativa. Puesto que la ciencia es, ante todo, la búsqueda de conocimiento verdadero, fecundo y coherente, la filosofía de la ciencia no debe interesarse en los valores que determinen la praxis científica, a no ser aquellos que nos impulsen a la búsqueda de ese tipo de conocimiento.

La filosofía de la ciencia de los años treinta-sesenta ha respondido plenamente a este tipo de planteamientos que separaban estrictamente la ciencia y los valores no epistémicos. Los debates entre los filósofos de la ciencia han estado centrados en cuestiones tales como si la ciencia es predictiva o no, si las teorias son comprobables, verificables o falsables, si una teoría se aproxima más a la verdad que otra, etc. Hablando en términos generales, se podría decir que, para la gran mayoría de los filósofos de la ciencia, el conocimiento científico debía ser descriptivo, explicativo, predictivo o comprensivo de lo que es, pero en modo alguno tenía que ocuparse de lo que debe ser: esto último era tema para personas interesadas en la ética, la política, la ideología o la religión. Mezclar cuestiones morales y argumentos científicos, de acuerdo con estas posturas, implica caer en lo que, desde Moore, se llama falacia naturalista. ${ }^{3}$

En este artículo se parte de una concepción muy distinta de la ciencia. Esta no es únicamente una actividad teorética, sino que incluye también acciones prácticas, y en concreto acciones transformadoras del mundo. La ciencia no se limita a indagar cómo es el mundo, sino que contribuye a modificarlo por doquier. Por consiguiente, la filosofía de la ciencia no se limita a estudiar el conocimiento científico sino que se ocupa también de la actividad científica. La filosofía de la ciencia no debe reducirse a una metodología ni a una epistemología de la ciencia, sino que ha de incluir una axiología de la ciencia. 
2. La separación entre la ciencia y los valores en la tradición empirista

$\mathrm{El}$ origen de las posturas filosóficas que separan estrictamente la ciencia y los valores no epistémicos hay que buscarlo en Locke y en Hume. En el último capítulo de su Ensayo sobre el entendimiento humano, Locke distinguió tres clases de Filosofía: la Física (o Filosofía Natural), la Filosofía Práctica (cuyo canon es la Ética) y la Semiótica o doctrina de los signos (es decir, la Lógica). Según Locke, éstas son alas tres grandes provincias del mundo intelectual, totalmente separadas y diferenciadas las unas de las otrass. ${ }^{4}$

Así como la Filosofía Natural (de la cual proceden las ciencias físiconaturales de la tradición positivista) tiene como finalidad "la mera especulación y el conocimiento de la verdad", 5 y por consiguiente sus cultivadores deben dedicarse a contemplar las cosas mismas para descubrir la verdad, ${ }^{6}$ la Filosofía práctica no tiene como finalidad el conocimiento de la verdad, "sino la justicia y una conducta acorde con ella". ${ }^{7}$ Ambos tipos de filosofía, según Locke, están estrictamente separados entre sí, y ello en virtud de la naturaleza de las cosas. Otro tanto sucede con la Lógica, o con las Ciencias Formales:

Ya que todo lo que puede caer dentro de la competencia del entendimiento humano es, primero, la naturaleza de las cosas como son en sí mismas, sus relaciones y su manera de operar; o segundo, aquello que el hombre mismo debe hacer, como un agente racional y voluntario, para alcanzar cualquier finalidad y especialmente su felicidad; o, tercero, las maneras y medios a través de los cuales el conocimiento de uno y otro aspecto se adquiere y se comunica, pienso que la ciencia se puede dividir propiamente en esas tres clases. ${ }^{8}$

El ser, el decir y el deber ser constituyen los tres grandes objetos de nuestro entendimiento. Lo notable es que Locke afirme una estricta separación entre los tres saberes correspondientes. De hecho, Leibniz criticó firmemente esa separación, en un tono bastante irónico:

[....] vuestras tres grandes regiones de la enciclopedia estarán siempre en continua guerra, pues cada cual se inmiscuye siempre en los derechos de las otras."

La frase de Leibniz se ha revelado profética. La separación entre la Filosofía de la Ciencia y la Filosofía Práctica difícilmente puede mantenerse hoy en día. En el fondo, restringir la Filosofia de la Ciencia a una filosofía del conocimiento científico es una tentativa de mantener la estricta separación lockeana entre la Ética y la Física, o si se quiere entre la Ciencia y la Moral. El problema estriba en que, por decirlo todavía en términos de Locke, si reconocemos que la ciencia es una actividad (o una praxis), inevitablemente nos veremos conducidos a solapamientos entre 
ambos tipos de Filosofía. ¿Por qué la ciencia, considerada como actividad, habria que tratar de hacerla bien? Esta es la pregunta clave en torno a la cuestión de la Ciencia y los Valores.

Sin embargo, la distinción de Locke, que se remonta históricamente a los estoicos, hizo fortuna. Las ciencias físico-naturales y las ciencias formales han formado en la tradición empirista, y mucho más en la positivista, dos mundos separados. iY qué decir de la filosofía moral! Siguen corriendo ríos de tinta para mostrar la irreductibilidad entre 'is' y 'ought'. ${ }^{\prime \prime}$

Dicha escisión se le ha solido atribuir a Hume. En su Tratado de la Naturaleza Humana, éste afirmó enfáticamente que:

[...] las distinciones morales no son producto de la razón. La razón es totalmente inactiva, por lo que nunca puede ser origen de un principio tan activo como lo es la conciencia o sentimiento de lo moral."

Partiendo de esta concepción contemplativa de la razón humana, cuyo origen se remonta hasta Pitágoras, Hume concluyó que:

Las acciones pueden ser laudables o censurables, pero no razonables o irrazonables. ${ }^{12}$

Merece la pena seguir la argumentación de Hume, quien, partiendo de esa concepción de la razón y de una gnoseología estrictamente empirista, escindió radicalmente la racionalidad y la acción humana. Por supuesto, hoy en día no se acepta esta última conclusión y se proponen con frecuencia teorías racionales de la acción humana. Lo notable es que ello siga haciéndose desde posiciones empiristas, para las cuales la falacia naturalista sigue siendo un criterio de evaluación filosófica: a partir de aserciones factuales no se pueden implicar aserciones morales. Los científicos pueden conjugar el verbo ser, pero no deben usar la expresión deber ser. Bien entendido que todo el argumento parte de la base de la naturalización de los hechos. En la medida en que, como afirmó Fleck y tras él numerosos sociólogos de la ciencia, haya una construcción social de los hechos, la falacia naturalista se desmorona.

Contrariamente a la tesis de Hume, según la cual la razón "consiste en el descubrimiento de la verdad o de la falsedad", ${ }^{13}$ aquí consideraremos que la razón humana, y en concreto la razón científica, es una potencia activa que tiende a transformar lo dado para mejorarlo. Los científicos nunca son inactivos frente a la naturaleza o al mundo, al menos si nos referimos a la ciencia actual. Precisamente por ello, desde una filosofía racionalista de la ciencia cabe hablar de acciones racionales e irracionales, sin prejuicio de que estas últimas puedan tener también sus motivaciones. Frente a la separación estricta que postuló Hume entre lo que él llamaba 
filosofía especulativa y filosofía práctica, y por consiguiente entre conocimiento científico y moral, conviene insistir en que incluso la investigación en las ramas más puras de la ciencia tiende siempre a transformar algo que venía dado previamente.

La actividad de los científicos no sólo es cognitiva. Frente a los filósofos y sociólogos de la ciencia que piensan que lo esencial de la ciencia es la investigación y la producción de conocimiento, hay que recalcar que la ciencia se convierte en un saber en la medida en que dicho conocimiento es enseñado, en primer lugar, y luego es aplicado por aquellos que lo han aprendido correctamente. Ni la aritmética ni la geometría habrian sido objeto de enseñanza a lo largo de los siglos si no hubiera sido porque permiten resolver de manera precisa y correcta numerosos problemas, tanto teóricos como prácticos. Contrariamente a la distínción tradicional entre contexto de descubrimiento y contexto de justificación, aquí partimos de la distinción de cuatro contextos en la actividad científica: el de educación, el de innovación, el de evaluación y el de aplicación. ${ }^{14}$ Cada uno de ellos posee sus propias peculiaridades desde un punto de vista axiológico.

\section{La separación entre ciencia y valores en Weber}

Los filósofos de la ciencia que se han inscrito en esta tradición lockeana y humeana, que posteriormente quedó apuntalada por Kant y por los neokantianos, ${ }^{15}$ han reducido la racionalidad de la ciencia a una racionalidad pura, y por consiguiente han separado estrictamente la ciencia y la axiología. Estas concepciones acabaron llegando a la propia sociología, a través de Max Weber. Como comenta Lamo de Espinosa:

Para Max Weber, como para los neokantianos, hay dos clases de ciencias -las naturales y las sociales-, completamente diferentes en sus objetivos y métodos. Las primeras son ajenas a la existencia de los valores; porque son formales trabajan con conceptos abstracto-generales y explicaciones causales. ${ }^{16}$

Las ciencias físico-naturales son consideradas como ciencias puras, con lo cual no sólo se alude a la distinción entre lo puro y lo aplicado, sino sobre todo a la ausencia o a la presencia de criterios axiológicos. Como suele decirse: una cosa son los juicios de hecho y otra los juicios de valor. Los científicos y los técnicos deben ser axiológicamente neutros, como lo son las ciencias físico-naturales. El mito de la neutralidad de la ciencia hunde sus raíces en esta tradición de pensamiento, que está sólidamente implantada en la ideología cientifista.

La teoría de la ausencia de valores (Wertfreiheit) en la investigación cientifica de la naturaleza fue ampliamente desarrollada por Max Weber. ${ }^{17}$ Puesto que los valores son culturalmente dependientes, la objetividad de la 
ciencia sólo puede estar garantizada en la medida en que, aunque en las ciencias sociales (y quizá también en otras ciencias) pueda haber referencia a valores, sin embargo no haya nunca juicios de valor. En sus escritos, el hombre de ciencia:

[...] debe indicar claramente al lector donde y cuándo temina de hablar eI cientifico y dónde y cuándo comienza a hablar el hombre de voluntad.13

Según Weber, los juicios de valor deben estar ausentes de las obras auténticamente científicas. En tanto observador del mundo (social, natural, histórico), el científico ha de guiarse por un único valor epistémico: la verdad. ${ }^{19}$

Este monismo axiológico no sólo ha caracterizado a buena parte de los filósofos de la ciencia, sino que influyó fuertemente en la sociología de la ciencia durante bastantes décadas. Desde las concepciones que se sustentan en este artículo, hay que afirmar, por el contrario, el pluralismo axiológico de la ciencia. La separación clásica entre hechos y valores, particularmente vigente en la filosofia kantiana, resulta obsoleta. Así como los hechos están cargados e impregnados de teoría, como afirmaron Popper y Hanson, y aceptan en la actualidad la mayoría de los filósofos de la ciencia, asî también hay que afirmar que la actividad científica está profundamente influida por diversos sistemas de valores, que habrá que intentar analizar y dilucidar.

\section{El Ethos de la ciencia, según Merton}

Cuando el sociólogo de la ciencia Robert Merton se ocupó de estudiar la estructura normativa de la ciencia, ${ }^{20}$ restringió su campo de estudio a las instituciones cientificas:

Ciencia es una palabra engañosamente amplia que se refiere a una variedad de cosas distintas, aunque relacionadas entre sí. Comúnmente se la usa para denotar: (1) un conjunto de métodos característicos mediante los cuales se certifica el conocimiento; (2) un acervo de conocimiento acumulado que surge de la aplicación de estos métodos; (3) un conjunto de valores y normas culturales que gobiernan las actividades llamadas cientificas; (4) cualquier combinación de los elementos anteriores. Aqui nos actuparemos, de manera preliminar, de la estructura cultural de la ciencia, esto es, de un aspecto limitado de la ciencia como institución. Así, consideraremos, no los métodos de la ciencia, sino las normas con las que se los protege. Sin duda, los cánones metodológicos son a menudo tanto expedientes técnicos como obligaciones morales, pero sólo de las segundas nos ocuparemos aquí. Este es un ensayo sobre saciología de la ciencia, no una incursión en la metodología.21

La tercera componente de las cuatro indicadas en su definición de ciencia le sirvió a Merton para definir el ethos de la ciencia como 
[...] ese complejo, con resonancias afectivas, de valores y normas que se consideran obligatorios para el hombre de ciencia. Las normas se expresan en forma de prescripciones, proscripciones, preferencias y permisos. Se las legitima en base a valores institucionales. Estas imperativos, transmitidos por el precepto y el ejemplo, y reforzados por sanciones, son internalizados en grados diversos por el científico, moldeando su conciencia científica. ${ }^{22}$

Esta definición del ethos científico nos servirá inicialmente, en la medida en que puede aplicarse a los cuatro contextos que hemos distinguido en la actividad científica. Cada uno de ellos, en efecto, posee sus propias normas, prescripciones y valores, así como su sistema específico de recompensas y sanciones. Contrariamente a lo que han pensado algunos sociólogos de la escuela constructivista, los estudios sobre la ciencia no deben reducirse, y ni siquiera centrarse en los laboratorios. Alli se están aplicando múltiples formas de saber previo para elaborar, producir o construir nuevo conocimiento científico; pero de ninguna manera cabe decir que de los laboratorios surja un nuevo saber científico. Para que las propuestas que surgen de los laboratorios lleguen a ser aceptadas como una nueva forma de saber científico han de someterse a otras muchas mediaciones sociales, que trascienden por completo al equipo de investigadores que discuten o consensúan en el laboratorio. La propuesta de Merton, en cambio, es lo suficientemente general como para que pueda ser aplicada a cada uno de los diversos escenarios institucionales en donde tiene lugar la actividad científica, y no sólo a los laboratorios.

En cualquier caso, Merton recalcó que la ciencia no sólo es un acervo de conocimientos acumulados y un conjunto de métodos conforme a los cuales se logra ese conocimiento, sino que también incluye una serie de prácticas sociales o comunitarias que están regidas por normas, valores, prescripciones y proscripciones. Además de una Epistemología y una Metodología, la Filosofía de la Ciencia debe incluir una Axiología de la Ciencia, al menos en la medida en que quiera aproximarse a la práctica científica real. De hecho, Merton insistió en que la práctica científica está determinada por reglas obligatorias, con lo cual señaló un aspecto muy relevante de la racionalidad científica, que apenas había sido considerado por los filósofos de la concepción heredada:

Las normas de la ciencia poseen una justificacion metodológica, pero son obligatorias, no sólo porque constituyen un procedimiento eficiente, sino también porque se las cree correctas y buenas. Son prescripciones morales tanto como técnicas. ${ }^{23}$

Cabría matizar esta última afirmación en una dirección medio leibniziana, medio popperiana: no es que las reglas que deben seguir los geómetras a la hora de medir longitudes o ángulos con regla o compás, o los 
físicos al manejar un instrumento de observación o de medida, sean buenas per se, en el sentido de que se dispone definitivamente de un buen instrumento y de unas buenas normas para utilizarlo. Lo que sí ocurre, en cambio, es que esos instrumentos y esas reglas son las mejores de que se dispone para obtener los correspondientes resultados, sin los cuales no podría proseguir la investigación científica. Los procesos de normalización que se llevan a cabo en el contexto de educación conllevan, ciertamente, la interiorización de una serie de normas para la práctica científica, y no sólo el aprendizaje de un acervo de conocimientos; pero nada impide que esas normas puedan ser mejoradas, por ejemplo inventando un nuevo algoritmo o proponiendo una nueva teoría del error. En una palabra: cada una de esas reglas es buena en el sentido de que nadie ha sabido proponer una regla mejor; pero la búsqueda de lo mejor siempre está abierta en la práctica científica.

Volviendo a Merton, éste inició una trayectoria mucho más problemática cuando trató de caracterizar en términos globales ese ethos científico, afirmando que «el objetivo institucional de la ciencia es la extensión del conocimiento verificado» y que "los imperativos institucionales (normas) derivan del objetivo y los métodos».24

Esta tesis proviene de la tendencia unificacionista y reduccionista que ha perjudicado a los estudios de muchos filósofos y sociólogos de la ciencia. Al centrarse exclusivamente en el conocimiento cientifico y en su expansión, Merton dejó de lado el contexto de aplicación, que constituye una de las grandes peculiaridades de la praxis científica.

Por el contrario, su distinción entre objetivos, valores y normas de la ciencia tiene gran interés para la filosofía de la ciencia. Al haber atribuido la primacía a los primeros, Merton caracterizó finalmente a la ciencia, desde el punto de vista axiológico, en función de una serie de objetivos globales de los que se desprendían los siguientes imperativos institucionales:

El ethos de la ciencia moderna incluye cuatro conjuntos de imperativos institucionales: el universalismo, el comunismo, el desinterés y el escepticismo organizado. .25

El universalismo incluía "el canon de que la afirmación que algo es verdad, cualquiera que sea su fuente, debe ser sometida a criterios impersonales preestablecidos". ${ }^{26}$ La raza, la nacionalidad, la religión, la clase y las cualidades personales del científico no deben influir en la aceptación o el rechazo de una propuesta científica. La ciencia es cosmopolita y universalista: «el libre acceso a la búsqueda científica es un imperativo funcionals.27

El «comunismo» mertoniano alude a la ciencia como producto de la 
colaboración social. La actividad científica es cooperativa y competitiva y, consiguientemente, debe ser comunicable. La ciencia moderna se caracteriza por la comunicación total y abierta, y no por el secreto, como ya había subrayado Bernal. ${ }^{28}$ Para Merton, el reconocimiento y la estima es la única forma de propiedad privada atribuible a los científicos, aunque la tendencia a patentar numerosos descubrimientos e innovaciones científicas, que él también comentó, parece desmentir esta tesis mertoniana. Asimismo el desinterés y el escepticismo parecen ser desiderata, más que rasgos éticos distintivos de la actividad científica.

De hecho, su propuesta fue criticada por diversos sociólogos de la ciencia y por algún filósofo. ${ }^{29}$ Desde nuestro punto de vista, la propuesta mertoniana resulta claramente insuficiente, pero tuvo al menos la virtud de señalar que la ciencia tiene una importante componente axiológica, punto éste que apenas había interesado a los filosofos de la ciencia, centrados siempre en la Epistemología y en la Metodología.

\section{El objetivo de la ciencia, seguin Popper}

En su Introducción de 1982 a La lógica de la investigación científica, Popper caracterizó su teoría de los objetivos de la ciencia como:

[...] la teoría de que la ciencia busca la verdad y la resolución de problemas de explicación, es decir, que busca teorias de mayor capacidad explicativa, mayor contenido y mayor contrastabilidad. ${ }^{30}$

La instauración popperiana de la verdad como valor predominante y su consiguiente caracterización global de la ciencia como una búsqueda sin término de la verdad, han tenido una influencia considerable en la filosofía del siglo Xx. Según Popper, el aumento del conocimiento, es decir el progreso científico, depende fundamentalmente de la revisión crítica de nuestras conjeturas previas. ${ }^{31}$ Esta tarea no tiene término, pero puede ser llevada adelante. Popper afirmó que no somos prisioneros ni de nuestras mentes ni de las valoraciones, creencias o dogmas de nuestro grupo social. ${ }^{32}$ Precisamente por ello la ciencia supera el subjetivismo, por una parte, pero también el comunitarismo, si entendemos por tal la determinación que las creencias (o intereses) de una comunidad científica puede ejercer en un momento histórico dado sobre la investigación científica:

La discusión racional y el pensamiento crítico no son como los sistemas primitivos de intetpretar el mundo; no son un marco al que estamos atados y amarrados. Por el contrario, son los medios para escapar de la prision, de liberarnos. ${ }^{33}$

Para Popper, el método de la ciencia se basa esencialmente en la crítica: 
[...] las teorías cientificas se distinguen de los mitos simplemente en que pueden criticarse y en que están abiertas a modificación a la luz de las críticas. No pueden verificarse ni probabilificarse. ${ }^{34}$

Por consiguiente, sólo cabe hablar de objetividad científica en la medida en que las conjeturas de los científicos han sido debatidas y sometidas a prueba mil veces. Como puede verse, la teoría popperiana de la ciencia conlleva una fortísima componente intersocial, puesto que esa actitud critica puede ejercerse desde cualquier cultura. La universalidad de la ciencia es un valor continuamente subrayado por Popper. La investigación científica a la que se refiere se lleva a cabo en un marco social, cultural, institucional e histórico determinado. Sin embargo, ello no implica que no podamos sobrepasar dicho marco, conduciendo nuestra indagación hacia una mayor universalidad. Al contrario: es lo que tenemos que hacer. A la teoria de Popper le subyace un fuerte imperativo moral, que es inseparable del objetivo propuesto por él para la ciencia:

Es cierto que dependemos de nuestra educación, nuestras creencias, nuestro conocimiento, nuestras expectativas. Pero también es cierto que no dependemos totalmente de ellos. Es indudable que sólo podemos liberarnos lenta y parcialmente de estas cadenas. Pero no hay límite natural para este proceso de liberación para el aumento del conocimiento. ${ }^{35}$

El racionalismo crítico popperiano está estrictamente basado en una teoría de lo mejor y de lo peor, y ello no en términos individuales ni culturales ni sociales, sino en términos de humanidad. La falsación y la crítica no sólo son preceptos metodológicos: en el caso de Popper, son también reglas propias del ethos de la ciencia. ${ }^{36}$

Popper concedio mucha importancia a las instituciones científicas y llegó a formular una minuciosa teoría al respecto: la ingeniería social fragmentaria, de la cual no nos ocuparemos aquí. ${ }^{37}$ Ello le llevó a formular una nueva característica universal para todo tipo de ciencias (formales, naturales, sociales), a saber, su carácter público. Y aunque Popper consideró esto como un "carácter del método cientiffico", ${ }^{38}$ no es difícil vislumbrar en esta característica un nuevo criterio axiológico, que Popper expuso en estos términos:

[...] decimos que una experiencia es «publica» cuando todo aquel que quiera tomarse el trabajo de hacerlo puede repetirla, ${ }^{39}$

para remachar a continuación:

Esto es lo que constituye la objetividad cientifica. Todo aquel que haya aprendido el procedimiento para comprender y verificar las teorías científicas puede repetir el experimento y juzgar por sí mismo. ${ }^{40}$ 
Las concepciones popperianas sobre la metodología de la ciencia están "cargadas de axiología", o si se quiere, de ethos científico. Popper afirmó en varias de sus obras que la objetividad de la ciencia debía ser entendida como intersubjetividad. Ahora bien, esa intersubjetividad no es reducible en absoluto a los procesos de consenso y de construcción de hechos (o de lenguajes) que estudian los sociólogos del conocimiento. En el caso de Popper, se trata de una intersubjetividad transcultural y transhistórica. Por muy diferente que sea el contexto cultural en el que Euclides escribió sus Elementos, lo cierto es que podemos repetir sus demostraciones muchos siglos después y juzgar por nosotros mismos si son válidas o no, y luego si son mejorables o no. Y otro tanto cabría decir de las ciencias físico-naturales. Las matemáticas (o la física) son ciencias objetivas porque son altamente intersubjetivas, y no porque los objetos de los que se ocupan existan o no, lo cual es una cuestión de indole muy distinta (ontológica, no epistemológica). La comunicabilidad del conocimiento científico (y en concreto la escritura) son condiciones sine qua non para que esa intersubjetividad sea factible.

Ahora bien, estas tesis de Popper ya no tienen que ver con la Metodología ni con la Epistemología, sino que conllevan una auténtica Axiología General de la Ciencia, o cuando menos unos primeros pasos tentativos en esa dirección. Podríamos decir, incluso, que el ethos de la ciencia, tal y como lo concibió Popper, conduce rápidamente a vincular la actividad científica con las formas políticas e institucionales de la sociedad concreta en donde la ciencia se elabora:

En último término, el progreso depende en gran medida de factores políticos, de instituciones politicas que salvaguarden la libertad de pensamiento: de la democracia. ${ }^{41}$

Se abre con ello otro campo de investigación para una filosofía de la ciencia que no esté aquejada de los síndromes empirista ni cientifista. Ia axiología de la ciencia subyacente a la teoría popperiana del objetivo de la ciencia nos muestra nuevos valores, que él considera fundamentales para el desarrollo de la actividad científica: por ejemplo la libertad de pensamiento y la libertad de crítica. Ello no equivale a decir que la democracia y la libertad sean condiciones necesarias para que haya ciencia. La historia muestra repetidas veces que no ha sido así. Sin embargo, tal y como el propio Popper subrayó, la ciencia siempre ha florecido en mayor medida cuando los regímenes imperantes en las sociedades correspondientes han sido democráticos. A pesar de que la ciencia es una actividad regulada y normativizada, la posibilidad de criticar y de mejorar dichas reglas siempre debe estar abierta. Para ello son imprescindibles: 
[...] las instituciones sociales, creadas para fomentar la objetividad y la imparcialidad cientifica; por ejemplo, los laboratorios, las publicaciones cientfficas, los congresos. Este aspecto del método científico nos muestra lo que puede lograrse mediante instituciones ideadas para hacer posible el control público y mediante la expresión abicrta de la opinión pública, aun cuando ésta se limite a un círculo de especialistas. ${ }^{42}$

En este pasaje Popper idealiza, sin duda, las instituciones científicas. Los sociólogos y los antropólogos de la ciencia han mostrado que las instituciones reales están muy lejos de estar regidas únicamente por los valores de objetividad e imparcialidad, y sus argumentos y estudios deben ser tenidos muy en cuenta por la filosofía de la ciencia. Desde nuestra perspectiva, nos interesa más mostrar que Popper sigue enunciando valores generales para la ciencia, siempre de carácter epistémico, como ahora la objetividad y la imparcialidad. Su metodología sigue estando cargada de axiología.

\section{Los valores y la ciencia, segun Kuhn}

En una conferencia pronunciada en 1973 bajo el título aObjetividad, juicios de valor y elección de teorían, Kuhn respondió a varios filósofos de la ciencia (Lakatos, Shapere, Scheffler) que habian criticado su obra de 1962, La estructura de las revoluciones cientificas, porque conducía a posturas irracionalistas en los procesos de elección de teorias.

Con el fin de disipar esos malentendidos sobre sus tesis de 1962, Kuhn se propuso responder a una pregunta que resulta particularmente interesante para nuestro objetivo en este artículo: ¿cuáles son las características de una buena teoría cientifica? Conviene subrayar que Kuhn se preguntó sobre cuándo una teoría es buena (o mala), y no cuándo es verdadera o falsa. Al proceder así, Kuhn apuntó a la existencia de valores científicos más amplios que los puramente epistémicos, como trataremos de mostrar a continuación.

Kuhn propuso inicialmente cinco características para dilucidar si una teoría es buena: precisión, coherencia, amplitud, simplicidad y fecundidad. Aunque repetidas veces señala que esas cinco características no son exhaustivas, y que podrían usarse otros listados, Kuhn insistió en que «estas cinco características son criterios estándares para evaluar la suficiencia de una teoriam. ${ }^{43} \mathrm{Su}$ argumentación sobre cada una de ellas fue la siguiente:

En primer término, una teoría debe ser precisa: esto es, dentro de su dominio, las consecuencias deducibles de ella deben estar en acuerdo demostrado con los resultados de los experimentos y las observaciones existentes. En segundo lugar, una teoria debe ser coherente, no sólo de manera interna o consigo misma, sino también con otras teorias aceptadas y aplicables a aspectos relacionables de la naturaleza. Tercero, debe ser amplia: en particular las consecuencias de una teoría 
deben extenderse más allá de las observaciones, leyes o subteoras particulares para las que se destinó en un principio. Cuarto, e íntimamente rclacionado con lo anterior, debe ser simple, ordenar fenómenos que, sin ella, y tomados uno por uno, estarian aislados y, en conjunto, serían confusos. Quinto -aspecto algo menos frecuente, pero de importancia especial para las decisiones científicas reales-, una teoría debe ser fecunda, esto es, debe dar lugar a nuevos resultados de investigación: debe revelar fenómenos nuevos o relaciones no observadas antes entre las cosas que ya se saben. ${ }^{4}$

Ninguno de estos criterios basta por sí solo para elegir entre dos paradigmas rivales. Y lo que es más: esa lista de criterios resulta ambigua a la hora de ser aplicada, tanto individual como colectivamente. Dos científicos distintos pueden obtener valoraciones diferentes respecto de una misma teoria a pesar de usar un mismo criterio, como por ejemplo el de fecundidad o el de coherencia. $Y$ desde un punto de vista colectivo, algunos criterios pueden oponerse a otros a la hora de evaluar teorías. Por eso Kuhn concluyó que:

[...] toda elección individual entre teorias rivales depende de una mezcla de factores objetivos y subjetivos, o de criterios compartidos y criterios individuales. Como esos últimos no han figurado en la filosofía de la ciencia, mi insistencia en ellos ha hecho que mis críticos no vean mi creencia en los factores objetivos. ${ }^{45}$

El proceso de evaluacion de teorías científicas rivales resulta ser mucho más complejo de lo que creyó la filosofía empirista de la ciencia. La valoración de un descubrimiento o de una nueva aportación científica no se lleva a cabo en función de un criterio único, como el mayor grado de corroboración o de falsabilidad. Los científicos poseen sus propias tablas de valores a la hora de enjuiciar las innovaciones, y por eso hay que distin- . guir, según Kuhn entre «criterios, reglas, máximas y valores». ${ }^{46}$

Nos interesará sobre todo su distinción entre, reglas y valores, porque esto le permitio afirmar que los criterios de elección entre teorías, y en concreto los cinco precedentes, funcionan como valores incompletos, y no como reglas de decisión. Científicos adscritos a los mismos valores pueden hacer valoraciones muy distintas de las teorías porque la aplicación de esos valores a la hora de enjuiciar las innovaciones científicas no es determinista, ni individual ni colectivamente. Si a la lista de cinco le añadiéramos un sexto valor, la utilidad social, las elecciones cambiarían, pareciéndose más a las que podría hacer un ingeniero: "las diferentes disciplinas se caracterizan, entre otras cosas, por conjuntos diferentes de valores compartidoss. ${ }^{47}$

La racionalidad científica depende así de una pluralidad de valores compartidos, cuya combinación fluctuante suscita la elección de unas teorias frente a otras. Contrariamente a aquellos autores que han tratado de 
aplicar la teoría de la decisión al problema de la evaluación de teorías cientifficas, ${ }^{48}$ para Kuhn no existe ningún algoritmo compartido de elección racional que pudiera dilucidar la mayor o menor cientificidad de las teorías científicas en virtud de su grado de corroboración (Carnap), de su grado de falsabilidad (Popper), de su aproximación a la verdad (escuela de Helsinki) o de su capacidad para la resolución de problemas (Laudan). La actividad científica en el contexto de innovación está regida por una pluralidad de valores, cada uno de los cuales genera criterios y reglas de evaluación diversos según los diferentes científicos y equipos investigadores:

[...] los criterios de elección con los cuales comencé no funcionan como reglas que determinan decisiones a tomar, sino como valores que influyen en éstas [...] valores como la precision, la coherencia y la amplitud pueden resultar ambiguos al aplicarlos, tanto individual como colectivamente; esto es, pueden no ser la base suficiente para un algoritmo de elección compartido. ${ }^{49}$

Esta es la respuesta básica que dio Kuhn a sus críticos; pero a nosotros no nos interesa tanto esa polémica, sino la constatación de que la investigación científica, y en concreto la elección entre teorías rivales, que Kuhn consideró como un "problema filosófico primordial»,50 está regida por una pluralidad de valores como los siguientes:

- precisión (o exactitud, o aproximación)

- coherencia (o consistencia)

- universalidad (o generalidad, o amplitud)

- simplicidad (o elegancia, o belleza)

- fecundidad (o progresividad, en el sentido de Lakatos)

- ajuste (o adecuación) a la naturaleza (o a los datos)

- utilidad social, etc.

Esta axiología de la ciencia a la que apunta Kuhn en relación al contexto de innovación tiene tres características de gran interés, que la distancian de otras muchas axiologías utilizadas implícitamente por los filósofos de la ciencia de tradición neopositivista o analítica: no es una axiología monista; no es reduccionista; no es fundacionista. Algunos sociólogos de la ciencia han tratado de explicar la actividad científica, y en concreto los procesos de elección entre teorías rivales, en función de intereses, y exclusivamente de intereses. Para ello han apelado con frecuencia a las propuestas de Kuhn. Sin embargo, puede comprobarse en estos textos que, para él, los valores que orientan la actividad investigadora de los científicos no determinan sus opciones teóricas ni sus criterios de elección, sino que simplemente influyen sobre los mismos. Lo esencial es buscar un cierto equilibrio, que siempre será dinámico, entre las diversas tentativas de 
realización de esos valores que los científicos pueden llevar a cabo a través de sus investigaciones y de sus propuestas teóricas. Contrariamente a lo que algunos filósofos más recientes han afirmado (Laudan, Chalmers, etc.), la ciencia no tiene un objetivo único del tipo saproximarse a la verdad", "conocer el mundo natural», "resolver problemas», etc. La actividad científica está regida en el contexto de investigación por una pluralidad de valores, como veremos con mayor detalle en los apartados siguientes.

Antes de abandonar este breve comentario a Kuhn, conviene subrayar uno de los tres problemas que señaló al final de su conferencia de 1973: la invariancia de los "valores científicos», entendiendo por tales los valores que rigen la investigación científica. Al respecto Kuhn afirmó lo siguiente:

En todo este artículo he venido suponiendo implicitamente que, independientemente de su origen, los criterios o los valores empleados en la elección de teoría son fijos de una vez y para siempre, y que no resultan afectados al intervenir en las transiciones de una teoría a otra. En términos generales, pero sólo muy generales, supongo que tal es el caso. Si se conserva breve la lista de valores pertinentes -mencioné cinco, no todos ellos independientes-y si se mantiene vaga su especificación, entonces valores como la precisión, la amplitud y la fecundidad son atributos permanentes de la ciencia. Pero basta con saber un poco de historia para sugerir que tanto la aplicación de estos valores como, más obviamente, los pesos relativos que se les atribuyen, han variado marcadamente con el tiempo y también con el campo de aplicación. Además, muchas de estas variaciones de los valores se han asociado con cambios particulares de la teoría científica. Aunque la experiencia de los científicos no justifica filosóficamente los valores que sustentan -tal justificación resolvería el problema de la inducción-, tales valores se han aprendido en parte de la experiencia y han evolucionado con la misma. ${ }^{51}$

El propio Kuhn señala a continuación que es preciso estudiar más a fondo este tema. Los valores científicos han cambiado a lo largo de la historia, tanto por su gradación como por su expansión. Algunos valores adquieren mayor peso en determinadas circunstancias historicas: baste recordar los profundos cambios axiológicos que experimenta la actividad investigadora en tiempos de guerra. Otros se propagan de unas disciplinas a otras, contribuyendo poderosamente a la aparición de nuevas disciplinas científicas: la matematización de las ciencias, entendida como un valor, y no simplemente como un método formalizador, representa un buen ejemplo, que el propio Kuhn menciona de alguna manera:

La precisión como valor ha venido denotando cada vez más, con el tiempo, concordancia cuantitativa o numérica, a veces a expensas de la concordancia cualitativa. Antes de los tiempos modernos, sin embargo, la precision en ese sentido era un criterio sólo para la astronomía, la ciencia de la región celeste. No se esperaba encontrarla en ninguna otra parte. En el siglo Xvi, sin embargo, el criterio de concordancia numerica se extendió a la mecánica; a fines del siglo xviI y principios 
del XIX pasó a la química y a otros campos como los de la electricidad y el calor, y en este siglo a muchas partes de la biologia. $O$ piénsese en la utilidad, valor que no figuró en mi primera lista. Ha venido figurando significativamente en el desarrollo científico, pero con mayor fuerza y de manera más estable para los químicos que para, digamos, los matemáticos y los físicos. O considerese la amplitud. Sigue siendo un valor cientifico importante, pero los grandes avances cientfficos se han logrado una y otra vez a expensas del mismo, y correspondientemente ha disminuido el peso atribuido a él en épocas de eleccion. ${ }^{52}$

No cabe hablar de una tabla permanente de valores científicos. Lo que Kuhn propone es un estudio histórico de los mismos, que hasta el momento está muy lejos de haber sido llevado a cabo. En cualquier caso, no cabe duda de que la racionalidad científica, según Kuhn, ha de basarse en una axiología de la ciencia, y no sólo en una metodología ni en una epistemología.

Como ya vimos en el apartado sobre Popper, y ratificamos ahora, cuestiones que han sido consideradas tradicionalmente como metodológicas o epistemológicas revelan nuevas facetas cuando son consideradas desde un prisma axiológico. No es lo mismo considerar la matematización de las ciencias como un método que vincular dicha metodología a los valores de rigor demostrativo y precisión conceptual y operativa que triunfaron en el ámbito de las matemáticas desde la emergencia de estas ciencias en Grecia: el more geometrico trajo consigo la primacía de una determinada tabla de valores científicos, que posteriormente fue siendo implementada y corregida por otras tablas de valores, como los procedentes de las ciencias baconianas o del criticismo kantiano. El avance de la estadística y de los métodos bayesianos no es ajeno a la afirmación de nuevos criterios de valoración de la actividad científica.

\section{Los valores epistémicos, según Laudan}

En 1984 Larry Laudan publicó un libro con el sugestivo título Science and Values, pero desde las primeras páginas anunciaba, con tono un tanto peyorativo, que no iba a ocuparse de las relaciones entre la ciencia y la ética, sino que se centraría exclusivamente en los valores epistémicos:

No tengo nada que decir sobre los valores éticos como tales, puesto que manifiestamente no son los valores predominantes en la empresa científica. Ello no equivale a decir que la ética no juegue papel alguno en la ciencia; por el contrario, los valores éticos siempre están presentes en las decisiones de los científicos y, de manera muy ocasional, su influencia es de gran importancia. Pero dicha importancia se convierte en insignificancia cuando se compara con el papel omnipresente (ubiquitous) de los valores cognitivos. Una de las funciones de este libro consiste en corregir el desequilibrio que ha llevado a tantos escritores recientes sobre la cicncia a estar preocupados por la moralidad cientifica más que por la racionalidad cientifica, que será mi tema central. ${ }^{53}$ 
El libro de Laudan tiene a Kuhn como punto de referencia principal. Ante las múltiples e interesantes sugerencias del autor de La estructura de las revoluciones cientificas, Laudan se propuso elaborar una teoría unificada de la racionalidad científica, que fue desarrollada con mayor amplitud en su libro previo El progreso y sus problemas..$^{54}$ Alli se había afirmado que «la ciencia es, en esencia, una actividad de resolución de problemas», 5 tesis en la que Laudan coincidia explícitamente con Popper y con Kuhn. Resolver problemas no se reduce a explicar hechos: hay numerosos hechos que durante largo tiempo no suponen problema científico alguno. Por otra parte, Laudan se desmarcaba de Popper al afirmar que «la verdad y la falsedad son irrelevantes para la resolución de problemas».56

Para desarrollar su teoría del progreso científico, Laudan tenía que afrontar inexorablemente dos cuestiones: la evaluación de problemas y la evaluación de teorías en tanto resolutorias de problemas. Siendo consciente de que los criterios de evaluación que usan los científicos cambian a lo largo de la historia, Laudan se vio llevado a afirmar un criterio de racionalidad basado en la idea de progreso: «la racionalidad consiste en la elección de teorías más progresivas». ${ }^{57}$ En ello coincidía casi por completo con Lakatos, quien, desarrollando a su vez algunas de la ideas de Popper, había llegado a identificar prácticamente la ciencia y el progreso. ${ }^{58}$ Sin embargo, la concepción que tiene Laudan del progreso científico resulta más explícita que la de Lakatos, y tiene que ver estrictamente con la capacidad de resolver problemas. Según él:

En el modelo de resolución de problemas, este análisis (el de coste/beneficio) opera como sigue: evaluar, para cada teoría, el número y la importancia de los problemas empíricos que se sabe resuelve; análogamente, analizar el número y la importancia de sus anomalías empíricas; por último, evaluar el número y la trascendencia de sus problemas conceptuales [...] nuestro principio del progreso nos aconseja preferir la teoría que más se acerca a resolver el mayor número de problemas empíricos importantes, al tiempo que genera el menor número de problemas conceptuales y anomalías relevantes..$^{59}$

Pudiera llamar la atención este recurso a la teoria económica de la racionalidad basada en los modelos de coste y beneficio, pero en las últimas décadas no resulta inhabitual encontrarse con este tipo de posturas entre los filósofos de la ciencia. ${ }^{\omega}$ Puesto que toda teoría puede resolver problemas, por una parte, pero también puede generar nuevos problemas (y entre ellos anomalías para los postulados de dicha teoría), la concepción laudaniana del progreso cientifico puede resumirse diciendo que la racionalidad científica consiste en maximizar los problemas resueltos y en minimizar las anomalías. Una tradición de investigación es progresiva en la medida en que maximiza la relación entre el beneficio epistémico y el coste epistémico. Puesto que la ciencia cuenta en todo momento, según 
Laudan, con tradiciones de investigación rivales, la evaluación entre teorías alternativas será racional si se opta por la más progresiva en el sentido antedicho:

[...] a la hora de evaluar los méritos relativos de las teorías, la clase de los problemas no resueltos es del todo irrelevante. Lo que importa a efectos de la evaluación de las teorias son sólo los problemas que han sido resueltos, no necesariamente por la teoria en cuestión, sino por alguna teoría conocida. ${ }^{6 i}$

La historia de la ciencia se presenta así como una competencia entre teorías y tradiciones de investigación rivales, expertas en la tarea de resolver problemas. En relación a los criterios axiológicos que se utilizan para evaluar las teorías y los problemas, Laudan sólo se ocupa de los valores epistémicos (verdad, coherencia, simplicidad y fecundidad predictiva), $o$, como también dice, de la evvaluación cognoscitivamente racionaln, ${ }^{62}$ Puede haber problemas muy importantes desde un punto de vista político o económico, pero éstos pertenecen a "las dimensiones no racionales de la evaluación de problemas».63 La filosofía de la ciencia no debe ocuparse de estas cuestiones, seguramente porque, según Laudan, desbordan el ámbito cognitivo o epistémico. A la hora de evaluar filosóficamente las teorías y las tradiciones de investigación, lo único que importa es la progresividad, en el sentido ya explicitado, y la adecuación, es decir la eficacia para resolver problemas epistémicos.

Comprobamos así adónde llevan las epistemologías que insisten en ser empiristas y demarcacionistas. Afirmar que las prioridades investigadoras de una institución pública o de una empresa de $I+D$ no son cognoscitivamente racionales equivale a reducir el concepto filosófico de la racionalidad cientifica a su mínima expresión. Ante el empuje de los diversos modos de estudiar la ciencia actualmente existentes (la historia, la sociología, la antropología, la ética, la filosofía política, etc.) reducir el papel de la filosofía de la ciencia a la evaluación de las cuestiones epistémicas equivale a renunciar por completo a analizar la praxis científica en toda su complejidad, por una parte, y a negarse a entrar en debates propiamente filosóficos con los demás expertos en los Science Studies. Curiosamente, estas opciones filosóficas que reducen la filosofía de la ciencia a una filosofía del conocimiento científico (puro), suelen luego reivindicar la dialéctica y la pluralidad de concepciones rivales como signo de la racionalidad y del progreso. A la hora de pronunciarse sobre cuestiones absolutamente candentes en la actividad científica actual, en cambio, prefieren guardar un silencio wittgensteiniano. 


\section{La concepción teleológica en filosofía de la ciencia}

En 1988, Eman McMullin editó un libro titulado Construction and Constraint, ${ }^{64} \mathrm{y}$ en él un artículo en el que abordaba dos cuestiones importantes: ¿cambia la racionalidad de la ciencia con el tiempo, y si lo hace, por qué razones?; ihay restricciones (constraints) especificas en dicho cambio? Para abordarlas, McMullin distinguía metas (goals or aims), métodos (means to an end) y valores en la actividad científica. Respecto a estos últimos, y contrariamente a las tesis tradicionales de la filosofía positivista, afirmaba que «los juicios de valor constituyen una parte importante de la metodología de la ciencian, ${ }^{65}$ así como que:

[...] cuando uno habla de la racionalidad de la ciencia, habitualmente se refiere de manera global a los métodos empleados por los científicos, así como a los valores que tratan de maximizar a base de aplicar dichos métodos. ${ }^{6 \hat{~}}$

Este tipo de tesis están siendo muy frecuentes en los últimos años, y han sido denominadas por Resnik como la concepción teleológica en metodología de la ciencia. Según este autor, la mayoría de los grandes filósofos de la ciencia han defendido esta concepción, al menos a partir de 1980: Rescher, Newton-Smith, Hempel, Levi, Popper, Laudan, Goldman y Giere han ido publicando libros desde 1977 hasta 1990 en los que, a veces aludiendo a los valores, a veces no, coincidían en afirmar que los métodos científicos son reglas prescriptivas para realizar los fines científicos.

Para Resnik, las dos grandes virtudes de esta concepción son su simplicidad y su atractivo. De hecho, califica a esa concepción como un utilitarismo epistémico, así como de racionalidad instrumental. ${ }^{67}$ En la medida en que concebimos la racionalidad científica en general como un conjunto de reglas metodológicas que rigen la praxis de los científicos, estando dichas reglas a su vez regidas por los grandes objetivos de la ciencia, no cabe duda de que disponemos de una teoría global sobre la racionalidad científica que no rehúye la cuestión de la ciencia y los valores. El problema subsiguiente consistiria en estudiar el vínculo entre las reglas y los fines, y para ello hay muchas opciones. Cada uno de los defensores de la concepción teleológica habría desarrollado su propia solución: la teoría de la decisión en el caso de Levi, ${ }^{68}$ la lógica y la teoría de la probabilidad en el caso de Popper, la ciencia cognitiva en el caso de Goldman ${ }^{69}$ y de Giere, ${ }^{30}$ la ciencia natural y la historia de la ciencia en el caso de Laudan o incluso el análisis en têrrminos de coste/beneficio, como vimos en el caso del propio Laudan y de Radnitzky. Poniendo como ejemplo a Newton-Smith, Resnik caracteriza la concepción teleológica mediante estos cuatro puntos: 
1) La ciencia tiene objetivos (fines o metas).

2) Los métodos científicos son reglas para la indagación que están justificadas (son racionales, están garantizadas, son aceptables) en tanto son medios efectivos de realizar (llevar a cabo, lograr) objetivos cientificos (epistémicos, cognitivos).

3) Los métodos son reglas prescriptivas que gobiernan las decisiones y las acciones científicas, por ejemplo, la aceptación de teorias, el diseño experimental y asi sucesivamente.

4) La racionalidad cientifica es una racionalidad instrumental (medios/fines), ${ }^{71}$

Los filósofos de la ciencia podrán luego diferir en los objetivos que consideran ser propios de la ciencia, así como en diversos matices de los cuatro puntos precedentes; pero, según Resnik, la gran mayoría de ellos acepta esta concepción teleológica como base para caracterizar la racionalidad científica. Incluso aquellos que afirman que la ciencia no es racional, recalca Resnik, conciben la racionalidad en términos instrumentales. ${ }^{72}$

Pasando a analizar cada uno de los cuatro puntos, lo primero que señala Resnik es que la ciencia, en tanto tal, no puede tener fines: sólo los seres intencionales pueden tener fines. Por consiguiente, cuando se habla del objetivo o de los objetivos de la ciencia será, o bien porque se piensa en metas compartidas, o en metas corporativas, o en ideales normativos o en características de la actividad científica.

Ninguna de estas cuatro posibilidades le satisface a Resnik, puesto que concluye:

He examinado cuatro diferentes interpretaciones de la frase cobjetivos de la ciencias $y$ he argumentado que ninguna de esas interpretaciones proporciona una justificación adecuada de las reglas metodológicas. Si pensamos en los objetivos como metas compartidas, entonces el pluralismo axiológico (entre los científicos) socava la justificación de las reglas metodológicas. Si pensamos en los objetivos como ideales normativos, entonces el pluralismo axiológico (entre los filósofos) también socava la justificación de las reglas metodológicas. Si pensamos en los objetivos como características que describen la conducta cientifica, entonces los objetivos no pueden justificar las reglas metodologicas porque esas características son demasiado generales y abstractas como para ofrecer una guía segura. Finalmente, pensar en los objetivos como metas corporativas tampoco ayuda, porque la ciencia no tiene nada que se parezca a una jerarquía corporativa. ${ }^{73}$

Cada una de estas conclusiones de Resnik, así como sus argumentaciones previas, podrían ser criticadas minuciosamente, pero no es éste el lugar en donde emprender esa tarea. Nos interesa más la claridad con la que ha planteado el debate contra la concepción teleológica, así como algunos puntos que nos van a servir para proseguir nuestra indagación. Sin embargo, antes de abandonar las tesis de Resnik, conviene mencionar al menos cuál es su postura final: 
Se pueden aprender dos lecciones a partir de esta discusion. Primero, deberfamos desarrollar una explicación alternativa, no teleológica, sobre la justificación de las reglas metodológicas. La idea de que los objetivos justifican las reglas puede funcionar para conductas individuales, orientadas a metas, o para conductas corporativas o de grupo, pero no se aplica a la ciencia. Segundo, los filosofos de la ciencia podrían lograr resultados más provechosos apartando su atención de los objetivos de la ciencia. Las cuestiones sobre los objetivos de la ciencia encantan a los filósofos, pero parecen tener poco efecto, si es que tienen alguno, sobre el trabajo de los científicos. ${ }^{74}$

Independientemente de nuestro desacuerdo con buena parte de las argumentaciones y de las tesis de Resnik, lo cierto es que su artículo destaca dos aspectos de la actividad cientifica que serán mury importantes en lo que sigue:

En primer lugar, Resnik reconoce claramente el pluralismo axiológico, tanto entre los científicos como entre los filósofos. Por consiguiente, puesto que la ciencia es plural tanto axiológica, como metodológicamente, aparte de ser plural como tal ciencia, podemos pensar en que no se trata de indagar la existencia de un objetivo o de un conjunto de objetivos para la ciencia, como tampoco se trata (contra la concepción heredada en filosofía de la ciencia) de buscar una metodología unificadora de la ciencia. La ciencia es plural desde muchos puntos de vista, y está muy bien que así sea. Ciencias distintas no tienen por qué compartir los mismos valores, por decirlo en nuestros términos. En segundo lugar, cabe hablar de una Axiología de la Ciencia sin tener que apelar a una Teleología de la Ciencia: Entre los muchos valores que rigen la actividad científica algunos funcionan teleológicamente con respecto a la ciencia; otros no.

Esta última afirmación merece una explicación, ya que, al menos entre los filósofos de la ciencia, suele hablarse de valores en términos de finalidades, en la medida en que se identifican los objetivos de la ciencia con los valores que rigen la actividad científica. Esto no tiene por qué ser así, como comprobaremos con mayor detalle en el apartado siguiente.

\section{Pluralismo y núcleo axiológico}

Considerada la ciencia como una actividad plural, y no sólo como la búsqueda de conocimiento, hay que atender a los valores y a las reglas que rigen dicha actividad en cada uno de los cuatro contextos de acción en los que puede ser analizada: el de educación, el de innovación, el de evaluación y el de aplicación. Al proceder así, estaremos en condiciones de poner en relación el pluralismo metodológico de la ciencia con el pluralismo axiológico inherente a la actividad científica.

Simplificando mucho, podríamos decir que, cuando hemos de evaluar proposiciones científicas, la adecuación entre los enunciados y los hechos, 
o entre el decir y el ser, al modo de los filósofos griegos, es un criterio axiológico relevante. Sin embargo, hay criterios adicionales de evaluación, como la claridad, la no trivialidad o la deducibilidad de dicha proposición. No todos los enunciados científicos pueden ser analizados directamente en función de su correspondencia con los hechos, como bien se ha visto en los debates entre los lógicos partidarios de una concepción de la verdad basada en la coherencia o basada en la correspondencia. Muchos enunciados, como por ejemplo las leyes, son lo suficientemente generales como para que su verdad y su falsedad no pueda ser dilucidada por simple corroboración empírica. En esos casos suelen deducirse consecuencias concretas a partir de las leyes, normalmente vinculadas a otros enunciados generales y a determinadas condiciones iniciales, de manera que su evaluación depende en primera instancia de su capacidad deductiva y predictiva. Una ley tiene mayor contenido empírico si de ella se derivan más predicciones concretas. La ley se confronta con los hechos de manera indirecta, a través de sus consecuencias.

En el caso de las matemáticas, resultan primordiales otros criterios: la consistencia, la coherencia, la decidibilidad, la independencia o la categoricidad de los sistemas formales han sido consideradas como propiedades metamatemáticas básicas. Aquí las consideramos como valores epistémicos. Pero también en el caso de las ciencias formales influyen otro tipo de valores, como la simplicidad o la belleza, así como la aplicabilidad o la fecundidad. Al considerar las propiedades metamatemáticas de las teorías como valores se advierte de inmediato que, además de los valores sintácticos y semánticos, hay que considerar también los valores prácticos o pragmáticos.

La verdad y la verosimilitud no son los únicos criterios de evaluación; en ocasiones, ni siquiera son los más decisivos a la hora de optar racionalmente entre dos o más teorías rivales. Las innovaciones científicas no siempre tienden a predecir hechos ni a explicar fenómenos. En determinadas fases de la actividad científica hay que controlar sobre todo el grado de precisión de los datos y de las medidas empíricas, presuponiendo un margen de error. No es lo mismo valorar una fórmula de la lógica matemática que un algoritmo o una tabla de datos observacionales. La primera puede ser evaluada directamente por sus valores de verdad o indirectamente por su capacidad deductiva, la cual depende de los sistemas axiomáticos en los que es una fórmula bien formada, mientras que el algoritmo será aceptado o no según su sencillez, operatividad, eficacia, rapidez o implementabilidad técnica, así como las tablas de datos lo serán por su precisión, exactitud, claridad, manejabilidad o por el simple hecho de ser fácilmente comprimibles. Cuando se habla de descubrimiento y de invención científicas, no sólo se alude a la demostración de un nuevo teorema, a la enunciación de una nueva ley o a la observación de un nuevo hecho. 
También son innovaciones los instrumentos de medida, de observación y de experimentación, las notaciones, los lenguajes y las representaciones informáticas, así como las técnicas de almacenamiento, recuperación y distribución de información y de conocimiento. Los criterios axiológicos que determinan la mayor o menor cientificidad de unas u otras innovaciones son muy diversos, y cambian con el tiempo.

Una fórmula matemática puede ser más o menos fiable, según que haya sido demostrada, sea una conjetura con alto nivel de verosimilitud o se trate simplemente de una formula heurística. Otro tanto sucede con los instrumentos y técnicas de observación y de medida: existe toda una teoria del error que determina los niveles de fiabilidad de dichos instrumentos. La evaluación de las propuestas científicas no sólo depende de su verosimilitud o de su capacidad deductiva (a partir de una ley cientifica o de un sistema de axiomas), ni tampoco únicamente de su precisión o exactitud (al medir, al observar, al calcular). Hay otros valores, como la simplicidad, la generalidad, la simetría o la belleza, que han jugado un importante papcl en muchos momentos claves de la historia de la ciencia. Asimismo hay que tener en cuenta la fecundidad y la potencialidad heuristica de las innovaciones científicas: una conjetura, un problema y una teoría pueden generar muchas propuestas científicas a pesar de que no sean demostrables en un momento histórico dado o no pucdan ser contrastables empíricamente. Valgan la teoría de la relatividad de Einstein, la hipótesis de Riemann o la propia teoría copernicana como ejemplos insignes de estos criterios de evaluación usados por los científicos, basados en nociones tales como «interesante", "sugerente", "prometedor", "fértil", "fecundo", "atractivo", etc. Una propuesta audaz, sorprendente o novedosa suele tener una buena recepción inicial por parte de la comunidad científica, siempre que esté bien presentada y argumentada, sin prejuicio de cuál sea su destino final.

Se afirma con ello que la valoración de las nuevas propuestas cientificas, sean éstas del tipo que sean (tcóricas, prácticas, observacionales, técnicas, terminológicas, taxonómicas, axiomatizadoras, aplicadas o simplemente pedagógicas), constituye un proceso. No hay experimento crucial ni bien supremo que determinen de una vez por todas el veredicto de los científicos con respecto a una innovación científica o técnica. La racionalidad de la ciencia tiene una complejidad mayor que lo que pensaron muchos filósofos empiristas de la ciencia cuando trataron de proponer un criterio único y definitivo para decidir sobre la cientificidad o no de un enunciado o de una teoría. La racionalidad científica es compleja precisamente porque recurre a varios criterios de evaluación, cada uno de los cuales interactúa con los demás.

Cuando hablamos de la ciencia en general, hemos de centrarnos en aquellos criterios axiológicos que, parafraseando a Lakatos, podrían ser denominados el núcleo axiológico de la actividad científica. Dilucidar algu- 
nos de estos valores resulta fundamental si queremos hacer una filosofía de la ciencia que estudie la actividad científica en toda su complejidad, y no sólo como actividad investigadora e innovadora. Esta insuficiencia aqueja a la gran mayoría de los filósofos y de los sociólogos de la ciencia (no asi a los historiadores), los cuales se han ocupado casi exclusivamente del contexto de descubrimiento y del contexto de justificación, desatendiendo los contextos de educación y aplicación y simplificando enormemente lo que es el contexto de evaluación. No sólo se evalúan teorías. La valoración de las propuestas científicas es un proceso iterativo que tiene Iugar a lo largo de todas las fases de la praxis científica. Reducir el problema de la evaluación al de la elección racional entre teorías altemativas equivale a no considerar más que la punta del iceberg de la praxis científica.

Aceptar que la filosofía de la ciencia debe incluir un estudio de la axiología de la ciencia implica aceptar que existen valores muy generales que priman sobre la casi totalidad de la praxis científica, incluida la producción de nuevo conocimiento. Entre dichos criterios axiológicos cabe anticipar los siguientes:

1. Los resultados de la actividad científica deben ser públicos, tarde o temprano, y no sólo privados.

2. Los resultados de la actividad científica deben ser comunicables y enseñables.

3. El saber científico debe ser accesible a cualquier ser humano, previa educación.

4. La objetividad prima sobre la subjetividad. O si se prefiere, la ciencia debe ser objetiva.

5. En la medida de sus posibilidades, los científicos deben tratar de mejorar lo logrado por sus predecesores.

Como puede verse, estos cinco criterios no están fundados en la condición natural de los seres humanos, sino que son valores sociales. Ha habido culturas y formas de saber en las que ni han imperado ni imperan esos valores. La cultura científica, en cambio, está regida por el principio de universalidad (referido a todos los seres humanos), del cual se desprenden los tres primeros criterios axiológicos.

Este primer elenco de valores no responde a un criterio demarcacionista: otras muchas actividades humanas pueden estar regidas por esos valores. Asimismo conviene subrayar que esta primera muestra de una axiología de la ciencia no es naturalista. A pesar de que, desde concepciones evolucionistas, pudiera pensarse que el anterior listado está determinado por el imperativo de una mejor adaptación de los seres humanos a su medio natural a través de la ciencia, por el momento dejaremos de lado 
este debate. Baste con subrayar que estos criterios axiológicos no incurren en la falacia naturalista, precisamente porque no están fundados en la naturaleza del ser humano, ni mucho menos en leyes naturales. Esos valores no se infieren a partir de hechos naturales. Antes al contrario. La existencia previa de esos valores determinará la aparición de numerosos aspectos fácticos en la actividad científica, tal y como ésta se muestra empíricamente en las sociedades en donde tiene plena vigencia. $O$ dicho de otra manera: ni la existencia de la ciencia, ni mucho menos su axiología, están garantizadas por ninguna tendencia natural. En la medida en que estos y otros valores dejen de estar vigentes socialmente, la ciencia podría desaparecer, o cuando menos verse relegada a una marginalidad social, como sucedió en Europa a lo largo de muchos siglos y como ha sucedido y sucede en otras muchas culturas. No hay ciencia sin una voluntad social de mantener dicha forma de actividad humana.

\section{La valoración en el contexto de educación}

La valoración de las propuestas y de las acciones de los científicos tiene lugar en todos los contextos de la ciencia, y no sólo en el de descubrimiento o innovación. También se evalúa, y mucho, el proceso de aprendizaje del conocimiento y de la práctica científica. Asimismo se evalúan los sistemas educativos en sus diversos niveles. El contexto de educación no se limita a ser una simple transmisión de conocimiento e información, sea ésta de tipo teórico o práctico. Al ser una actividad que tiende a transformar el mundo (en este caso transforma a seres humanos), las personas, los instrumentos y las instituciones en donde se lleva a cabo esta labor deben ser valoradas y mejoradas una y otra vez.

También se evalúan los resultados de esta labor transformadora: por ejemplo la asimilación, memorización e interiorización de los contenidos enseñados, sin perder nunca de vista la capacidad de innovación y de crítica que el sciturus pueda manifestar a lo largo del aprendizaje. La acción educativa debe producir unos efectos transformadores sobre el mundo donde se ejerce, que en este caso son personas. Ello no sólo implica adquisición de información o conocimiento, sino también destrezas y habilidades prácticas: de poco le sirve a un matemático saberse la teoría si luego no sabe hacer por sí mismo las demostraciones o no consigue resolver los problemas. Y otro tanto cabría decir, aún en mayor grado, de los futuros científicos experimentales.

La educación es una acción normalizadora, por una parte, pero también potenciadora del librepensamiento, de la crítica y de la capacidad de invención. Siendo estrictamente acumulativa, es decir, estando planificada en los contenidos y en los métodos, el orden en que se accede a los mismos resulta fundamental. Los conocimientos teóricos y prácticos que ca- 
racterizan a la ciencia sólo son accesibles en la medida en que se haya acreditado una competencia previa en los niveles educativos precedentes. La educación cientifica es un proceso continuamente iterado de construcción de saber teórico y práctico. Por eso adopta la forma de saber sobre el mundo. En ningún contexto como el educativo fracasa tanto la regla metodológica de Feyerabend, todo vale. Y puesto que la enseñanza de la ciencia es condición necesaria para la reproducción y la mejora del conocimiento científico, sería un error ignorar los valores que rigen esta fase de la actividad científica: orden, claridad, capacidad formativa, potenciación del espíritu crítico, etc.

Los propios evaluadores y enseñantes han de ser evaluados para comprobar si su actividad docente es conforme a los contenidos previstos, sugerente en las formas y eficaz en los resultados. Asimismo hay que evaluar las técnicas, los instrumentos y los métodos pedagógicos. Y no están exentas de evaluación las propias instituciones y comunidades científicas. Ya en el contexto de enseñanza y dífusión de la ciencia, por consiguiente, hemos de tomar en consideración múltiples criterios posibles de evaluación, con frecuencia de índole muy diferente.

Sin embargo, dicha diversidad de valores no implica una multiplicidad informe. Hay valores centrales que rigen más que otros la práctica científica en los diversos contextos, y en particular en el contexto de educación. El principal de todos ellos, al menos desde que la ciencia se convirtió en uno de los motores de la Ilustración, es la comunicabilidad de los contenidos científicos a cualquier ser humano; de éste se deriva la exigencia de publicidad. El conocimiento cientifico ha de poder ser comunicado y enseñado públicamente, lo cual equivale a decir que todo ser humano ha de tener posibilidades de acceder a él: e incluso obligatoriamente hasta una cierta edad, como muchos Estados han determinado en sus Constituciones. Aunque Feyerabend haya puesto en cuestión la obligatoriedad de la enseñanza de la ciencia ${ }_{r}{ }^{75}$ la consideración de ésta como un bien público de toda la humanidad ha regido y rige el contexto de enseñanza y de difusión del saber científico, salvo excepciones y preocupantes retrocesos.

Como consecuencia, hay otro valor central para la actividad científica en este primer contexto que, aunque se deduce de lo anteriormente dicho, conviene subrayar: se trata de la universalidad o cosmopolitismo del saber científico. Dicho en otros términos: los contenidos científicos han de poder ser enseñados en cualquier lengua, independientemente de que unas lenguas estén más desarrolladas que otras por lo que respecta al vocabulario o al uso de términos científicos. Dentro del contexto de enseñanza, la ciencia es expresable en cualquier lengua, es traducible, sin perjuicio de que pueda haber paradigmas inconmensurables en un momento histórico dado. Las tesis de Kuhn sobre la inconmensurabilidad o la intraducibilidad, así como las tesis previas de Quine, no afectan para nada a este valor 
fundamental de la educación científica. Tanto el saber teórico como el saber práctico de los científicos es translingüístico y transcultural.

Ello no equivale a decir que la ciencia pueda surgir a partir de cualquier lengua o de cualquier cultura, ni tampoco que la ciencia no transforme las lenguas y las culturas. Como ya se ha indicado, siguiendo a Popper en este punto, hay formas sociales que son más propicias que otras para el desarrollo de la actividad científica. Además de una actividad, la ciencia es un trabajo, y hay culturas que han dedicado mucho mấs esfuerzo que otras a esta tarea. Por consiguiente, la ciencia es translingüística y transcultural, sin perjuicio de que su inserción en una lengua o en una cultura produzca cambios culturales y sociales cualitativos. Como se dijo desde el principio, la ciencia es una actividad transformadora del mundo, y por ende también de las culturas y de las lenguas. La implantación de la educación científica obligatoria en una cultura supone uno de los principales programas de transformación cultural posible, sin perjuicio de que dicho programa de acción educativa haya de ser a su vez valorado, tanto desde el punto de vista de su pertinencia y de su oportunidad como desde el punto de vista de la estrategia o de los resultados que ofrece.

El carácter público y cosmopolita de la ciencia no han venido dados. No son naturales. No son cuestiones que dependan de la relación entre la Ciencia y la Naturaleza. Son logros culturales y sociales, o si se prefiere progresos de la cultura cientifica. Con ello estamos afirmando que no sólo hay progreso científico desde el punto de vista de la metodología, de la matematización, de las aplicaciones científicas o de la mejora del conocimiento del mundo. La ciencia también progresa por otras vias, como es la asimilación social de determinados valores que rigen la práctica científica. La publicidad y el cosmopolitismo son valores básicos en el contexto de educación, sin perjuicio de que también sean criterios axiológicos importantes en los restantes contextos. Lo que ocurre es que, en el caso del contexto de educación, la comunicabilidad, la publicidad, la traductibilidad y el cosmopolitismo son valores centrales, y por consiguiente constitutivos de lo que llamaremos el nucleo axiológico de la actividad científica educativa.

En cambio, en el contexto de aplicación no tienen esa función central, aun siendo valores a tener en cuenta. A la hora de aplicar el conocimiento cientifico, puede haber grandes diferencias entre las diversas culturas y zonas geográficas: la utilidad, la adecuabilidad y la pertinencia son criterios axiológicos mucho más importantes en el contexto de aplicación que la publicidad y el cosmopolitismo. Bueno es que se hagan públicas las componentes de un determinado producto farmacéutico o de un alimento envasado, así como su fecha de caducidad; bueno es que haya un registro público (y a poder ser internacional) de patentes; pero estos dos valores no ocupan en el contexto de aplicación el lugar absolutamente central que les corresponde en el contexto de educación. 


\section{La valoración en el contexto de innovación}

Si pasamos al contexto de innovación, antes llamado contexto de descubrimiento, no cabe duda de que, pese a que los criterios de evaluación también son múltiples en este caso, también es posible distinguir componentes de un núcleo axiológico, que pueden quedar suficientemente representados por algunos de los valores epistémicos ofinalidades de la ciencia que han investigado los epistemólogos y los filósofos de la ciencia a lo largo del siglo XX. El conocimiento cientifico ha de poseer una estructura lógica y un armazón metodológico, sin perjuicio de que los criterios metodológicos, e incluso los lógicos, puedan variar a lo largo de la historia. La generalidad, la coherencia, la consistencia, la validez, la verosimilitud y la fecundidad han solido ser consideradas como condiciones sine quae non para que algo sea aceptado como científico. Estos criterios de valoración, ampliamente estudiados y comentados por los lógicos, metodólogos y epistemólogos, forman parte de lo que aquí hemos llamado el núcleo axiológico de la ciencia en el contexto de innovación. Una hipótesis ha de ser verosímil, en el sentido de que debe adecuarse a los hechos. Un razonamiento debe ser válido. Generalizar un teorema siempre se considera que es un avance científico. Las teorías deben ser coherentes y consistentes, y a poder ser fecundas, en el sentido de que permitan la generación de nuevos hechos, nuevos resultados y nuevos problemas. La capacidad para resolver problemas previamente planteados la incluimos dentro de este criterio axiológico al que llamamos fecundidad.

Pero hay que señalar que, por lo que respecta al contexto de innovación o de descubrimiento, el núcleo axiológico tampoco se reduce a estos criterios epistémicos. También hay que incluir en ese núcleo algunos valores que son prerrequisitos de los anteriores, por una parte, así como una serie de valores pragmáticos que suelen tener aplicación general.

La objetividad, entendida al modo de Popper, es uno de ellos. Una determinada innovación debe poder ser reproducida por personas o grupos diferentes a aquellos que la propusieron. El conocimiento científico se distingue en esto de otras formas de conocimiento, como el de los místicos o los sabios zen. Por ello las propuestas de los científicos han de ser reproducibles en ámbitos distintos a aquellos en donde se produjeron. De nada sirve construir hechos en un laboratorio o llegar a procesos de consenso en ese escenario si luego esos hechos o esos consensos no son reproducibles por otros agentes científicos. Si una demostración, una observación, un proceso de medición o un experimento no fueran reproducibles por doquier y por cuảlquiera, no podrían ser admitidos como ciencia.

Otro valor importante es la utilidad, bien sea teórica, bien sea práctica. El hecho de que una teoría sea predictiva implica una utilidad epistémica, pero puede haber innovaciones científicas, como las de los matemá- 
ticos, que son útiles porque permiten resolver problemas prácticos: calcular con mayor rapidez, lograr unos resultados más exactos, etc. La utilidad es un valor clave, no solo en el contexto de apiicaciòn, síno tambiên eñ ei de innovación.

Vayamos a los valores propiamente pragmáticos. La honestidad es uno de ellos, entendiendo por tal la no apropiación de descubrimientos o invenciones ajenas, la mención a las fuentes en las que uno se ha basado, la veracidad de los datos empíricos obtenidos, o simplemente y por resumir, la opción en contra de la mentira y del engaño: cuando Popper hablaba de la búsqueda de la verdad, mezclaba criterios axiológicos epistémicos y pragmáticos. La competencia en el uso de los instrumentos científicos (sean éstos artefactos materiales o conceptuales) es un segundo criterio de valoración de la praxis científica, y con frecuencia es usado como indicador previo, antes de aplicar otros valores. Así como en el contexto de educación se suele estar atento a las faltas de ortografía o a las incorrecciones sintácticas (por ejemplo un programa informático mal escrito), así también la destreza en el uso de las herramientas cientificas suele ser un indicador de la fiabilidad o credibilidad de los científicos y de sus propuestas. Podrian mencionarse otros valores de índole pragmática, pero los dos mencionados pueden bastar, al menos a título provisional.

La libertad de investigación es asimismo un valor central en este contexto, sin perjuicio de que pueda quedar atemperado por otros valores, como el control social de la investigación científica. Llegados a este punto, entramos en uno de los debates centrales de la axiología actual de la ciencia, en el que los filósofos de la ciencia deben participar, sin ninguna duda. Afirmar que estos valores, o sólo uno de ellos, forman parte del núcleo axiológico en el contexto de innovación equivale a optar por teorias axiológicas contrapuestas, que a nuestro modo de ver tienen mucho más interés en la actualidad que el debate sobre la corroborabilidad o la falsabilidad, por poner un ejemplo de debate sobre una axiología exclusivamente epistémica. Una política científica que promueve acciones concretas en el contexto de innovación siempre trata de producir transformaciones sociales, y no sólo progreso del conocimiento. Optar por un núcleo axiológico u otro, considerando como valor central el control social de la ciencia, o, por el contrario, afirmar que la libertad de investigación es un valor central, mientras que el control social es un valor periférico, que sólo debe aplicarse en casos extremos, todo ello da lugar a políticas de investigación científica estrictamente opuestas. Por consiguiente, también en el contexto de innovación cabe hablar de la ciencia como una acción racional regida por una pluralidad de valores, entre los cuales hay varios que son epistémicos, pero también otros que son prácticos.

La axiologia que determina y orienta en cada momento histórico las diversas acciones de los científicos es, como vemos, plural, y no está exen- 
ta de tensiones internas, como sucede con todo sistema de valores; pero esa pluralidad está estructurada y determinada, en primer lugar por los cuatro contextos ya aludidos, en segundo lugar por los respectivos núcleos axiológicós, y en tercer lugar por el grado de optimización del sistema de valores al que llegue cada axiología concreta. Desde este tercer punto de vista, que resulta ser el determinante a la hora de evaluar las grandes innovaciones científicas (como las teorías que implican cambios revolucionarios) hay que analizar los diversos grados de primacía de cada valor en función del contexto del que nos ocupemos, del tipo de ciencia que analicemos y del marco histórico y social en que la actividad científica tenga lugar. La idea central que aquí se defiende es que no debe pensarse que hay un valor preponderante, por mucho que en algunos momentos históricos ello puede suceder: por ejemplo en caso de guerra, en donde el patriotismo prima como valor pragmático y los programas de investigación se definen y se seleccionan estrictamente en función de las necesidades más perentorias de la defensa y en donde los propios científicos son movilizados y pasan a trabajar en aquellos puestos que sean considerados más útiles para el objetivo social preponderante.

Aparte de este núcleo axiológico, la evaluación de las innovaciones cientificas y técnicas tiene en cuenta otros muchos criterios, y por ello constituye un proceso mucho más complejo de lo que creyeron los filósofos analíticos. Una buena axiomatización y un buen método de presentación del conocimiento científico (Euclides, Newton, Mendeleiev, Zermelo, etc), al igual que una convincente refutación experimental de una teoría tradicionalmente admitida (la del flogisto, la del éter, la del creacionismo biológico, etc.), representan importantes bazas a la hora de valorar una teoría o una práctica científica. La ciencia se desarrolla muchas veces con independencia de los grandes criterios de valoración y de justificación epistémica o conceptual, teniendo en cuenta axiologías mucho más concretas. Desconocer estas microvaloraciones de los descubrimientos y de las invenciones cientificas implica tener una concepción idealizada y abstracta de la actividad científica. Sería como si pensáramos que las sociedades y los individuos se mueven y actúan en función de las grandes ideologías. Sería, por consiguiente, hacer ideología de la ciencia, y no filosofía de la ciencia.

\section{La valoración en el contexto de aplicación}

Si pasamos a considerar el contexto de aplicación, los criterios axiológicos se amplian todavía más. Desde Bacon, la ciencia moderna ha tenido una componente aplicada que no puede ser dejada de lado a la hora de hacer una consideración filosófica no reduccionista de la actividad científica.

La utilidad puiblica (o privada) de las innovaciones científicas, sean 
éstas teorias o sean simplemente artefactos que puedan ser usados en la vida cotidiana (medicinas, alimentos, electrodomésticos, etc.), pertenece al núcleo axiológico del contexto de aplicación. Incluimos en este valor tanto los beneficios y los daños sociales que puede producir una innovación tecnocientífica a la hora de ser aplicada (por ejemplo un medicamento o un artefacto como el automóvil) como los beneficios y las pérdidas económicas que los procesos de innovación suelen ocasionar entre empresas y ramas completas de la industria. Otro valor nuclear es la eficacia: entre dos propuestas tecnocientíficas rivales se prefiere (o se considera mejor) aquella que resuelve más eficazmente un determinado problema. $Y$ no hay que olvidar el coste: dado que el contexto de aplicación de la ciencia incide fuertemente en la economía y en la sociedad, y suele requerir inversiones considerables, los aspectos económicos de la actividad científica, que por supuesto ya están presentes en los contextos de educación y de innovación, pasan aquí a tener una importancia mucho mayor. La axiología de la ciencia en el contexto de aplicación no suele ser autónoma, precisamente porque, al aplicarse, la ciencia interactúa con otras formas de actividad social. En concreto, los criterios de valoración que se aplican en este contexto suelen estar íntimamente emparentados con lo que genéricamente se llama evaluación de tecnologias. ${ }^{76}$

En el contexto de aplicación cabe distinguir también entre valores epistémicos y valores prácticos. La función explicativa de la ciencia, e incluso su función predictiva (de los fenómenos, del mundo, de los desastres naturales, de las enfermedades, etc.), pueden ser considerados como valores epistémicos particularmente relevantes en el contexto de aplicación. Siempre conviene recordar a este respecto que el mismo Newton argüía que sus teorías sobre la gravitación, en la medida en que explicaban y predecían la aparición de los cometas, tendrían un efecto social beneficioso, porque contribuirían a que remitieran los desórdenes sociales que en su época ocasionaban las apariciones de los cometas. Otro tanto cabe decir de la meteorologia, de la medicina o de la biología, y en general de las ciencias con una vocación aplicada más fuerte. En ellas los valores epistémicos están estrechamente vinculados a los valores prácticos.

Hablando en términos generales, cabe decir que el contexto de aplicación está determinado por un valor básico, que podríamos resumir con el siguiente verbo: mejorar. Si la ciencia posee valores aplicados es porque la actividad científica está guiada por el principio de lo mejor. La contribución de la ciencia a unas mejores condiciones para la habitabilidad, el desplazamiento, la alimentación, la procreación, la salud o la comunicación entre los seres humanos, son sin duda algunos de los grandes expónentes del progreso científico, considerado desde el punto de vista del contexto de aplicación.

Pero existen otros muchos valores que han estado o pueden estar vi- 
gentes en el contexto de aplicación de la actividad científica. Pongamos un ejemplo: la ciencia ha estado estrechamente vinculada a lo largo de la historia a la actividad militar. La invención de nuevas armas que pudieran ser aplicadas eficazmente contra el enemigo, por mencionar el caso más característico, constituye una de las aplicaciones históricamente más notables de la ciencia. Ello ha dado lugar a auténticas crisis de valores en algunos científicos, en particular cuando determinadas innovaciones científicas eran valoradas en función de su capacidad destructiva, o más concretamente por la mejora de la capacidad destructiva (o defensiva) con respecto al armamento del que disponía el enemigo. Desconocer esta faceta de la actividad científica, y en particular la transmutación de valores a la que da lugar este ámbito de aplicación, equivaldría a hacer una filosofía bienpensante de la ciencia, y escasamente analítica, por cierto. Los valores que rigen la actividad científica en tiempo de guerra han de ser estudiados minuciosamente, porque en estos momentos históricos se muestra hasta qué punto el núcleo axiológico de la ciencia cambia radicalmente. Estas crisis de los valores científicos, que han de ser cuidadosamente distinguidas de las crisis de paradigmas, suclen manifestarse subjetivamente en forma de crisis de conciencia de los científicos y de sus comunidades; mas también de manera objetiva, en la medida en que las líneas de investigación se modifican fuertcmente, y no sólo desde el punto de vista de las aplicaciones, sino incluso de las teorías. Muchos científicos experimentan esas crisis de valores como auténticas contradicciones de la actividad científica, que de ninguna manera son epistémicas, sino prácticas. Podemos concluir, por consiguiente, que hay crisis axiológicas en la ciencia, y no sólo crisis de los paradigmas epistémicos (o crisis de fundamentos).

La ciencia contemporánea ha revelado otro aspecto de la actividad científica aplicada que conviene resaltar, y que tiene que ver con lo que hay que empezar a llamar economía de la ciencia. No sólo afecta al contexto de aplicación. También la investigación científica, e incluso la propia enseñanza de la ciencia, poseen una componente económica que cada vez va siendo más importante. Por una parte la ciencia se ha profesionalizado, con la consiguiente generación de puestos de trabajo públicos y privados que tienen que ver de una manera o de otra con la actividad científica, y que dan lugar a todo un sector económico, cada vez más relevante en los países desarrollados. Por otra parte, Ja investigación científica, y en concreto los procesos de innovación, requieren grandes inversiones económicas para ser llevados a cabo. Ello da lugar a que numerosos descubrimientos e invenciones requieran una costosísima infraestructura económica como condición de posibilidad. Por consiguiente, cabe distinguir entre actividades científicas caras y baratas, y ello ya en el contexto de enseñanza y de innovación.

Sin embargo, es en el contexto de aplicación en donde el circuito eco- 
nómico de la actividad científica se completa y deviene más significativo, motivo por el cual los criterios de evaluación de la actividad científica desde el punto de vista económico han de ser tratados fundamentalmente en este cuarto contexto. La innovación científica y tecnológica va siendo una fuerza productiva cada vez más importante, que genera a veces enormes beneficios económicos y puede ocasionar cambios en el propio modo de producción social. Consiguientemente, la rentabilidad y el impacto económico y social de las aplicaciones científicas (y no sólo de la tecnología) pasan a ser criterios importantes de valoración de la ciencia, a veces por encima de la utilidad pública a la que hicimos alusión anteriormente.

La profesionalización de la actividad científica ha producido una estrecha vinculación entre la ciencia y el mercado de trabajo. Todo ello equivale a decir que la generación de riqueza económica, o en términos más generales, la mejora economica, ha pasado a ser un criterio axiológico cada vez más relevante para la actividad científica. Hay numerosas innovaciones científicas y tecnológicas que son patentadas inmediatamente, con lo cual se entra en tensión con el valor clásico de la publicidad del conocimiento científico, reapareciendo tendencias hacia la privatización del saber científico, cuando no hacia el secretismo.

Para terminar este breve vistazo a algunos de los aspectos axiológicos de la actividad científica, conviene insistir en que no cabe hablar de una jerarquía estable e intemporal dentro de esa pluralidad estructurada de valores que vamos esbozando. En algunos momentos históricos (caso de las guerras o de los grandes desastres naturales: sequías, epidemias, etc.) y en algunas disciplinas, la aplicación de la ciencia prevalece sobre los valores exclusivamente epistémicos. También sucede al revés, como muestra el caso de las matemáticas y de la investigación básica, sin perjuicio de que también las matemáticas han estado determinadas muchas veces por sus aplicaciones, incluidas sus aplicaciones a la guerra (véanse Arquímedes, Vieta, Nobel, o más recientemente Von Neumann con la aplicación de los ordenadores recién descubiertos al proyecto Manhattan).

Consiguientemente, cuando los filósofos de la ciencia se aplican a la valoración y a la justificación de la ciencia, no deben recurrir a tablas de valores rígidas. La actividad científica no sólo es dinámica porque se desarrolla a lo largo de la historia y porque la ciencia se aplica a la transformación de la realidad; la ciencia posee también una dinámica propia, que no sólo tiene que ver con la historia interna de los conceptos o leyes cientificas, sino también con las oscilaciones de los criterios axiológicos internos y externos que marcan los objetivos de la actividad científica. Los criterios de evaluación interactúan entre sí, y pueden llegar a ser contradictorios en determinados momentos. La ciencia no está exenta de oposiciones axiológicas. Lo importante es la optimización de la pluralidad de valores vigentes a la que se llegue en cada momento. No es lo mismo una ciencia que se 
desarrolla en una economía socializada, en la que el Estado es el principal potenciador de la actividad científica, que una ciencia desarrollada en empresas privadas regidas por una tabla de valores en los que el beneficio y la competividad suelen ser predominantes.

\section{La axiologia de la ciencia: consideraciones finales}

Como hemos visto en los apartados precedentes, el contexto de evaluación interactúa con los otros tres contextos. El contexto de evaluación deviene así el ámbito por excelencia para la filosofía de la ciencia. Partiendo de esta perspectiva, caben dos líneas básicas de trabajo:

1. Estudiar la axiología de la ciencia tal y como ésta se produce empíricamente en la actividad de los científicos, y ello tanto a nivel individual como a nivel de grupo, a nivel institucional o a nivel social. Este trabajo debe ser llevado a cabo en colaboración con los historiadores y los sociólogos de la ciencia, así como con los expertos en la incidencia de la tecnologia sobre la sociedad.

2. La filosofía de la ciencia, sin embargo, no tiene por qué reducirse a la tarea anterior. O lo que es lo mismo, la filosofía de la ciencia no tiene por qué ser sólo un saber de segundo nivel (o metacientífico). En la medida en que la filosofía de la ciencia incluya una Axiología, además de una Metodología y una Epistemología de la Ciencia, la filosofía de la ciencia tiene un segundo ámbito de estudio que ya no depende de cómo efectivamente haya sido o sea la ciencia, sino de cómo debería ser. La filosofía de la ciencia no ha de ser normativa respecto a los contenidos de la ciencia, ni tampoco respecto a la Metodología. Es imprescindible aceptar y promover el pluralismo metodológico de la ciencia, en lugar de regresar a los programas unificacionistas. Sin embargo, la filosofía de la ciencia sí puede analizar y promover nuevos valores, tanto epistémicos como prácticos, que puedan ser innovaciones axiologicas para los propios científicos.

De hecho, éste ha sido el papel histórico de muchos filosofos en relación con la actividad científica: baste recordar a Bacon, a Descartes, a Locke o a Kant, por no remontarnos hasta el propio Aristóteles, quien generó una duradera Axiología de la Ciencia, que ha perdurado durante siglos. En la medida en que los filosofos de la ciencia, tras llevar a cabo minuciosos estudios empíricos sobre los valores vigentes en la actividad científica, sean capaces de analizar, recomponer y mejorar los sistemas de valores de los científicos en sus diversos contextos, la filosofía de la ciencia puede ser una actividad de primer orden en su relación con la ciencia, y no sólo una actividad metacientífica. Cuando se pide la presencia de filósofos para evaluar tecnologfas o para estudiar las consecuencias que determinadas innovaciones cientificas pueden tener sobre la sociedad, no se busca una filosofia de la ciencia lastrada por el prurito cientifista, sino una 
que afirme resueltamente su voluntad transformadora del mundo desde su conocimiento de las diversas formas de saber que caracterizan a los seres humanos, y entre ellas el saber científico.

La filosofía de la ciencia no puede seguir reduciéndose a una epistemología, ni debe seguir ocupándose únicamente de los valores epistémicos. En la medida en que sepa vincular los valores propios de la actividad científica con los que rigen la actividad económica, o la actividad política, - la actividad artística o la actividad religiosa, por mencionar sólo unas cuantas de las prácticas sociales de mayor influencia, la filosofía de la ciencia estará contribuyendo a vincular estrechamente la cultura científica con otras formas de cultura humana. El programa demarcacionista que trató de separar a los filósofos de los restantes gremios que se ocupan de estudiar la ciencia, y de los propios científicos y tecnologos, es un programa que debe pasar a la historia de la filosofía de la ciencia.

\section{NOTAS}

1. Este artículo ha sido elaborado en el marco del Proyecto de Investigacion PB92-0846C06-01 financiado por la Dirección de Política Científica del Ministerio de Educación y Ciencia, sobre el tema "Aspectos pragmáticos de las teorias científicas".

2. Entre los muchos autores que cabria citar al respecto, mencionaré a Laudan como cjemplo: «Mi tema en este libro no son los valores morales, sino los valores cognitivos; no son las normas éticas ni las normas de conducta, sino las reglas y normas metodológicas. [...] En suma, éste es un libro sobre el papel de los valores cognitivos en la formación de la racionalidad cientificas (L. Laudan, Science and Values, Berkeley, Univ. of Califomia Press, 1984, pp. XI y XII).

3. Vease G.E. Moore, Principia Ethica, Cambridge, Cambridge Univ, Press, 1903. Para un amplio estudio sobre la falacia naturalista, puede verse el libro de M. Ruse, Taking Darwin Seriously, Oxford, Blackwell, 1986, cap. 6.

4. J. Locke, Ensayo sobre el entendimiento humano, Madrid, Ed. Nacional, 1980, vol. II, p. 1,070 .

5. Ibid, p. 1.068 .

6. Ibid, p. 1.069 .

7. Ibid., p. 1.068 .

8. Ibid., p. 1.067.

9. G.W. Leibniz, Nuevas Ensayos sobre et entendimiento humano, Madrid, Ed. Nacional, 1983 , p. 640.

10. Vease, por ejemplo, el capítulo 7 del libro de R.D. Masters, Beyond Relativism. Science and Human Values, Hanover, Univ. Press of New England, 1993, cap. 7. Masters se opone a esa escisión entre ser y deber ser.

11. D. Hume, Tratado de la Naturaleza Humana, III, 1, 1, p. 676 de la edición de Félix Duque en Madrid, Ed. Nacional, 1977.

12. lbid.

13. Ibid, p. 675 .

14. Ver J. Echeverria, "Crítica a la distinción entre contexto de descubrimiento y contexto de justificacion: una propuesta alternativa», Revista Latinoamericana de Filosofia, XX: 2 (1994), pp. 283-302.

15. En su Fundamentación de la metafísica de las costumbres, cuando Kant se pregunta, poco antes de llegar a la Observación final, "cómo la razón pura puede ser práctica», su 
respuesta es contundente: «todo esfuerzo y trabajo que se emplee cn buscar explicación de esto sert perdidom (trad. de Manuel Garcia Morente en Madrid, Espasa-Calpe, 1967, p. 135). Dentro del sistema kantiano, esta tesis resulta probablemente imprescindible, dada la manera en que define a la razón pura (como ausencia de voluntad). Lo grave es que este sistema de pensamiento haya servido como punto de partida a tantos filósofos de la ciencia que han incluido, automáticamente, la ciencia en el ámbito de la razón pura, y en todo caso la tecnología (o la ciencia aplicada) en la práctica. A nuestro modo de ver, aunque aquí no vayamos a desarrollarlo, la ciencia moderna, y en particular la contemporánea, es uno de los ejemplos más claros de lo que Nietzsche llamaba voluntad de poder.

16. E. Lamo, J.M. González y C. Torres, Sociologia del conocimiento y de la ciencia, Madrid, Alianza, 1994, p. 85.

17. Véase su obra Sobre la teoria de las ciencias sociales, Barcelona, Península, 1971.

18. Ibid., p. 19.

19. Véase un excelente resumen de la teoria weberiana de los valores en la ciencia en $E$. Lamo, J.M. Gonzalez y C. Torres (1994), p. 89.

20. Véase R.K. Merton, La sociología de la ciencia, Madrid, Alianza, 1977, vol, 2, pp. 355-368.

21. Bid., pp. 356-357.

22. R.K. Merton, wLos imperativos institucionales de la ciencias, en B. Bames y otros, Estudios sobre sociologia de la ciencia. Madrid, Alianza, 1980, p. 66.

23. Merton, o.c., p. 359.

24. Ibid., p. 67.

25. Ibid.

26. Ibid.

27. Ibid, p. 69.

28. «El crecimiento de la ciencia modema coincidió con un definido rechazo del ideal del secretom (J.D. Bernal, The Social Function of Science, Londres, Routledge \& Kegan Paul, 1939, pp. 150-151).

29. Véase, por ejemplo, Michael Mulkay, «El crecimiento cultural en la ciencian, en B. Bames y atros, Estudios sobre sociologia de la ciencia, Madrid, Alianza, 1980, pp*125-140: Ver tambien L. Laudan (1992), pp. 156-157.

30. Realismo y el objetivo de la ciencia (1985), p. 40.

31. K.R. Popper, Realismo y el objetivo de la ciencia, Madrid, Tecnos, 1985, p. 195.

32. Ibid., pp. 194-195.

33. Ibid., p. 195.

34. Ibid., p. 47.

35. Ibid., p. 196.

36. lbid, $_{1}$ p. 29, en donde reconoce que su metodología de la ciencia conlleva una propuesta normativa.

37. Véanse La Sociedad abierta y sus enemigos, capitulos 9 y 23, y La miseria del historicismo, capítulos $20,21,24$ y 32 .

38. La Sociedad abierta y sus enemigos, Buenos Aires, Paidós, 1982, p. 381.

39. Ibid., p. 386 .

40. Ibia.

41. La miseria del historicismo, Madrid, Alianza, 1987, p. 170.

42. La Sociedad abierta y sus enemigos, 1982, p. 386.

43. Ibid., p. 346.

44. Ibid., pp. 345-346.

45. Ibid., p. 349.

46. Bbid., p. 354.

47. Bid., p. 355.

48. Véase, por ejemplo, los capítulos 13 y 14 de la obra de R.N. Giere, Understanding Scientific Reasoning, Nueva York, Holt, Rinehart \& Winston, 1979. 
49. T,S. Kuhn, La tensión esencial, Madrid, FCE, 1983, p. 355.

50. Ibid., p. 358.

51. lbid., p. 359.

52. Ibid., pp. 359-60.

53. L. Laudan, Science and Vatues. The Aims of Science and their Role in Scientific Debate, Berkeley, Univ. of Califomia Press, 1984, p. XII.

54. Publicado en 1977. Existe traducción española en Madrid, Encuentro, 1986.

55. Ibid., p. 39.

56. Ibid., p. 54

57. Ibid, p. 33.

58. Vease I. Lakatos, La metodología de los programas de investigación cientifica, Madrid, Alianza, 1983, p. 54 .

59. L. Laudan, El progreso y sus problemas, 1986, p. 16.

60. En este sentido destaca G. Radnitzky, quien aplicó sistemáticamente los métodos de coste y beneficio (cost-benefit analysis, $C B A$ ) a cuestiones relevantes de la metodología de la ciencia. Véase su articulo "The Economics of Scientific Progress", Annals of the Japan Association for Philosophy of Science, 7: 2 (marzo de 1987), pp. 85-99.

61. L. Laudan, El progreso y sus problemas, 1986, p. 51 .

62. L. Laudan, Science and Values, 1986, p. 63.

63, lbid.

64. E. McMutlin, "The Shaping of Scientific Rationality", en E. McMullin (ed,), Construction and Constraint, Notre Dame, Univ, of Notre Dame Press, 1988.

65. Ibid., p. 23.

66. Ibid.

67. D.B. Resnik, "Do Scientific Aims Justify Methodological Rules?», Erkenntnis, 38 (1993), pp. 223-232, esp. pp. 223 y 224.

68. I. Levi, The Enterprise of Knowledge, Cambridge, MTT Press, 1980.

69. A. Goldman, Epistemology and Cognition, Cambridge, Harvard Univ. Press, 1980.

70. R. Giere, Explatining Science, Chicago, Univ. of Chicago Press, 1990.

71. D.B. Resnik, o.c., p. 224.

72. Ibid, p. 225.

73. Ibid., p. 230.

74. Ibid., p. 231 .

75. Véase P.K Feyerabend, La ciencia en una sociedad libre, Madrid, Siglo XXI, 1982.

76. Sobre este tema, que no abordaremos en esta obra, pueden verse las diversas obras publicadas por el INVESCYT (Instituto de Investigaciones sobre Ciencia y Tecnología), por ejemplo la obra cditada por Manuel Medina y José Sanmartín, Ciencia, Tecrología y Sociedad, Barcelona, Anthropos, 1990, asi como las publicaciones de la serie Impactos de la editorial Fundesco, por ejemplo el libro editado por Roberto Dorado y otros, Ciencia, Tecnologia e Inciustria en España, Madrid, Fundesco, 1991. 